\title{
Multi-wave differential optical absorption spectroscopy surface ozone measurement with open path meters
}

\author{
Leonid Balatsko, Victar Dziomin, Aliaksandr Krasouski, \\ Alexander Liudchik and Victar Pakatashkin \\ National ozone monitoring research and education centre, \\ Belarus
}

\section{Introduction}

Most of the scientific research activity has focused on the atmospheric boundary layer, where the photochemical smog constituents reach to high concentrations, resulting thus to the often occurrence of air pollution episodes, especially over mega-cities (Jacovides al., 1994; Kondratyev \& Varotsos, 1996, 2002; Ozone monitoring, mapping, and public outreach, 1999; Varotsos et al., 2001, 2005). Surface ozone is known as one of the most important air pollutants, therefore, much attention is paid to ozone concentration monitoring.

Nowadays photometric surface ozone concentration meters are being widely exploited. These instruments employ a principle of taking for the analysis air samples at a local point of space (List of designated reference and equivalent methods, 2000; Girgzdiene \& Girgzdys, 2003; Гиргждене et al., 2008). To provide high quality measurements (Klausen et al., 2003) with the instruments of such type their periodic calibration against the travelling (mobile) standard is used everywhere. The results of calibration allow to introduce correction into measurements for the given ozone analyzer.

Besides the air sampling technique a method for measuring surface ozone and other small atmosphere constituents by sounding an open lengthy path with radiation becomes quite popular (Bolot'ko et al., 2004, 2005, 2007, 2008a, 2008b; Edner, 1993; Krasouski et al., 2006; Opto-analyser AR-500. User's manual, 1993; Platt et all., 1979; Transceiver-130. User's manual, 1994). The main advantage of such an approach is a possibility to extend results of measurements over a rather large area, since the method gives concentrations averaged over a long path instead of ones measured at a local point. It is clear that the averaged in space concentrations are less sensitive to the influence of such (hardly estimating and depending on sampling place and time) factors as local air microcirculation features and their variability under changing meteorological conditions (Bolot'ko et al., 2007). The advantages of the open path measurements are displayed most effectively in the multipath version of the instrument presented by the OPSIS firm (Transceiver ER-130. User's manual, 1994). A source of radiation and an instrument receiver are placed in one module (to return radiation from a path corner (retro) reflectors are used). This modification provides measurements of the gas average concentration to be analysed in different directions from 
the radiator-receiver over a path about $250 \mathrm{~m}$ length. Such advancing of the idea of the open path measurements makes them similar to lidar systems but provides in contrast to the latters a metrological accuracy of measurements. The authors of this chapter prefer open path measurements namely for this reason and have been intensively working for several years to design construction of the instrument and develop methods of measurements (Bolot'ko et al., 2004, 2005, 2007, 2008a, 2008b). To specify further discussion, theoretical results will be applied mainly for the TrIO-1 device as well as a procedure used to measure ozone concentration.

Quite evident, that checking and calibration of open path meters can not be performed by means of the travelling standard, since there is no possibility to fill the path of sondage with calibrated quantity of the gas to be analysed. The idea of calibration by measurements on parallel paths also raises valid objection. That's why, a fundamentally different approach based on the principle of measurements absoluteness is required to solve the problem of quality of open path measurements.

Formally, a photometric method (like in meters with air sampling) and a spectrophotometric method of differential optical absorption spectroscopy (like in the case of measurements on the open path) are both absolute ones, because they give a possibility to measure target concentrations without any prior calibration against a standard instrument. One has to satisfy only definite requirements on the instrument alignment and to determine contributions to a resulting uncertainty of ozone concentration from main sources of this uncertainty.

This study aims at presenting formulation of the multi-wave method for open path surface ozone concentration meters and assessing the effect of several typical sources of the uncertainty in the surface ozone concentration which are common with open path meters.

The mathematical formalism of the multi-wave method provides a possibility to link directly resulting ozone concentration with measured optical signals. Proposed mathematical formalism is universal and can form a basis for the analysis of various approaches towards measuring concentrations of small gas components of the atmosphere by the DOAS-method. A method applied for the OPSIS firm instruments (Opto-analyser AR-500. User's manual, 1993) is discussed as an example of such analysis in section 5. The formalism also enables to evaluate influence of different sources of errors on the results of ozone concentration measurements in terms of general approach. To realize this, random and systematic errors in the instrument parameters and the calculation method as well as the uncertainties of signal measurements are interpreted as the distinction of sounding radiation spectra on working and reference paths. Estimating further the effect of such distinction on the results of calculation, it is possible to determine the role of each error source in the formation of resultant uncertainty of the measured ozone concentration. We have derived analytical expressions to assess the influence of error sources of different nature on the results of ozone concentration definition by means of the open path technique. Numerical values of the contribution to the resultant ozone uncertainty from several error sources are given as an example for the multi-wave method implemented for the TrIO-1 instrument.

Some results of surface ozone concentration measurements with the TrIO- 1 device at the Minsk ozone station of the National ozone monitoring research and education centre (NOMREC) are presented at the end of the chapter. 


\section{An open path ozone concentration meter TrIO-1}

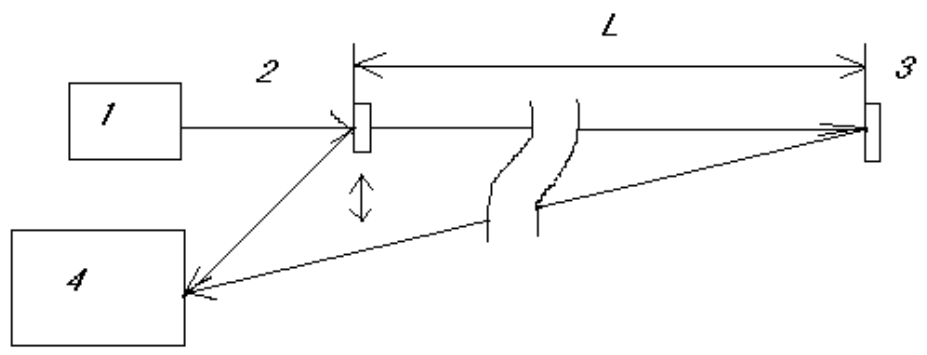

Fig. 1. A simplified optical scheme of the TrIO-1 meter. 1 - the source of radiation, 2 - the moveable mirror to create the reference path, 3 - the reflecting mirror of the open path, 4 the spectrometer with the fore optics and the unit of registration

The device TrIO-1 is designed in NOMREC to measure average ozone concentration along the open path of sondage with the ultraviolet radiation (Bolot'ko et al., 2004, 2008a). The instrument consists of 4 main modules (see figure 1):

1. The source of ultraviolet radiation (a halogen lamp; the unit 1 in the figure 1 );

2. The mirror to reflect radiation on the working path to the receiver (the unit 3 in the figure 1);

3. The moveable mirror to form by a relocation of the mirror the reference path of a short length without absorbing substances (the unit 2 in the figure 1);

4. The spectrometer including a photoreceiver and a corresponding electronics to register optical signals on the working and reference paths at the selected working wavelengths (the unit 4 in the figure 1). A special fore optics including an interference filter set at the entrance of the spectrometer to plain a spectral intensity of the sounding radiation.

The TrIO-1 instrument has some characteristic properties being different from known open path gas analyzers.

1. The TrIO-1 employs the spectral interval of 260-295 nanometers assigned to a longwave region of the ozone absorption band for measurements of ozone concentration. An appearance and a significant growth of the scattered sun radiation intensity on the wavelengths exceeding 295 nanometers stipulate this choice. Correcting for such radiation is impossible.

2. Unlike the techniques usually used in DOAS-analyzers, a measurement of concentration in TrIO-1 is accomplished at a smooth region of the ozone absorption band.

3. A short reference path is applied in the device to maintain the regular control of intensity of the sounding radiation flow directed to a working path. An optical thickness of the reference path practically equals zero.

The construction of the device differs from the majority of the OPSIS open path instruments since the latter does not use a reference path, and the source and the receiver are placed at the different ends of the working path. Meanwhile, the OPSIS model Transceiver ER-130 
(Transceiver-130. User's manual, 1994) combines the emitter and the receiver in the one module. Thus, the TrIO-1 instrument is closer by a construction to the latter.

Two optical path surface ozone concentration meters TrIO-1 were made and put into operation in the middle of 2004. One instrument is located at the Station of a combined background monitoring of the Berezina biosphere reserve $\left(54^{\circ} 44^{\prime} \mathrm{N}, 28^{\circ} 21^{\prime} \mathrm{E}\right)$ which is considered as a vast ecologically clean zone. The second instrument is run at the Minsk ozone station of NOMREC $\left(53^{\circ} 50^{\prime} \mathrm{N}, 27^{\circ} 28^{\prime} \mathrm{E}\right)$. At the ozone station we have in operation a certified ozone analyzer TEI $49 \mathrm{C}$ to conduct a scientific research and maintain the quality control of the measurements received from the TrIO-1 meter.

\section{Multi-wave technique of open path measurements of the surface ozone concentration}

Differential optical absorption spectroscopy is based upon the Bouguer-Lambert-Beer law. A spectrophotometric method for measuring concentrations of atmosphere components can be formally considered as an absolute one, since it does not require any preliminary calibration against the reference instrument. However, the absoluteness of a method for open path measurements cannot be provided without taking into account imperfection of radiation sources and optical systems for measurement.

Unlike the devices dealing with air samples pumped into a photometric cell, open path meters perform measurements of gas concentrations along a lengthy path directly in the atmosphere. In that case it is impossible to remove the analysed gas from the path of sondage to estimate the intensity of the sounding radiation emitted on the path. That's why, open path measurements need more than one wavelength of the sounding radiation per one gas to be analysed. Formally, two wavelengths are sufficient for one atmosphere constituent to be defined (Bolot'ko et al., 2005). Moreover, an additional reference path of a small length excluding influence of radiation absorbers is used to determine spectral distribution of sounding radiation. In some cases (for example for the device TrIO-1) reflecting mirrors returning sounding radiation are installed at the ends of both paths. The reflection spectral factors coincide for both mirrors. In other modifications a source of radiation and a receiver can be placed at the different ends of a path; it is not essential for a developed technique. In all cases the length of the open path exceeds $100 \mathrm{~m}$. For TrIO-1 meters the spectral interval of measurements is equal to $260-300 \mathrm{~nm}$.

The signal measured at a wavelength $\lambda$ can be presented in the form of

$$
S_{\lambda}=g \gamma_{\lambda} I_{\lambda} \exp \left(-\tau_{\lambda}\right)
$$

where:

$g$ - is the geometrical factor, describing radiation attenuation on the path due to the divergence of the radiation beam, limited sizes of the mirrors, nonselective attenuation of the radiation on the path, etc. The geometrical factor, by definition, does not depend on the wavelength, but, it differs for different paths;

$\gamma_{\lambda}$ stands for the absolute spectral sensitivity of the device. To simplify the notation, we have included spectral dependence of the mirrors reflection in $\gamma_{\lambda}$;

$I_{\lambda}$ - is spectral density of the radiation intensity emitting to the path. In general, it depends on the path type, i.e. working (open, sounding, etc.) or reference; 
$\tau_{\lambda}$ - is the optical thickness of the path. In case of the reference path $\tau_{\lambda 0} \equiv 0$ (further the reference path $(0)$ and the working path $(l)$ will be marked with the second index, where it is necessary).

Optical thickness of the working path is the sum of optical thickness of ozone absorption $\tau_{\mathrm{O} 3 \lambda}$, optical thickness of molecular scattering $\tau_{\mathrm{mol} \lambda}$ and optical thickness of radiation attenuation by aerosols and precipitations $\tau_{\text {aer }}$. The latter can be viewed as a wavelength independent in a rather narrow working spectral interval. Thus,

$$
\tau_{\lambda l}=\tau_{\mathrm{O} 3 \lambda}+\tau_{\mathrm{mol} \lambda}+\tau_{\mathrm{aer}}
$$

Assuming spectral nonselectivity of $\tau_{\text {aer }}$, it can be included in the geometrical factor of the working path. Thus, the geometrical factor ceases to be a device constant and starts to depend on the measurements conditions ( $\tau_{\text {aer }}$ value), but, that is allowed by the proposed technique. A contribution to the optical thickness $\tau_{\mathrm{mol} \lambda}$ is calculated by means of known formulas (Frohlich \& Shaw, 1980; Bolot'ko et al., 2005). A contribution due to the ozone absorption is proportional to the average ozone concentration along the sounding path $n$ and the path length $l$ :

$$
\tau_{\mathrm{O} 3 \lambda}=\sigma_{\lambda} n l
$$

where $\sigma_{\lambda}$-is a cross-section of radiation absorption at a wavelength $\lambda$ by ozone.

The negligible contributions due to radiation absorption by other small gas components (for example, $\mathrm{SO}_{2}$ and $\mathrm{NO}_{2}$ ) are not accounted in equation (2). Estimations show that these contributions in a working spectral range are inappreciable comparing to the ozone absorption.

Let us introduce designations:

$$
\begin{gathered}
z_{\lambda}=\ln \left(S_{\lambda 0}\right)-\ln \left(S_{\lambda l}\right)-\tau_{\mathrm{mol} \lambda}, \\
G=\ln \left(g_{0} / g_{l}\right)+\tau_{\mathrm{aer}}, \\
X=n l .
\end{gathered}
$$

Then, combining the expressions (1) - (6), yields

$$
z_{\lambda}=G+X \sigma_{\lambda}
$$

According to (4), values $z_{\lambda}$ can be considered as transformed registered signals from the reference and working paths, including errors of various origin. $G$ and $X$ parameters are subject to determination. Equation (7) due to errors in measured signals and approximations used can not be satisfied with fixed values of $G$ and $X$ for all $z_{\lambda}$ if a number of working wavelengths exceeds 2 . Still, this relation can be viewed as the equation for the straight line drawn by means of the least squares method through the range of experimentally measured values $z_{\lambda}$ that are related to the set of selected values of $\sigma_{\lambda}$. Thus, minimizing the sum of 
squared deviations of the equation (7) from really measured values $z_{\lambda}$ (Bolot'ko et al., 2008b), yields

$$
\begin{aligned}
& X=D_{z \sigma} / D_{\sigma \sigma}, \\
& G=z_{\mathrm{av}}-\sigma_{\mathrm{av}} X
\end{aligned}
$$

where $D_{a b}=\sum_{1}^{N}\left(a_{i}-a_{\mathrm{av}}\right)\left(b_{i}-b_{\mathrm{av}}\right), \quad a_{\mathrm{av}}=\frac{1}{N} \sum_{1}^{N} a_{i}$ - is the average value of the set $a, N-$ is the total number of working wavelengths. In the case of $a=b$ the covariance $D_{a b}$ reduces to a dispersion of $a$.

\section{Influence of sounding radiation spectra discrepancy over the reference and working paths}

Consider a case when a spectrum of sounding radiation on the reference path doesn't coincide with a spectrum on the working path. The distinction in spectra can be referred to the light beams of different temperatures irradiated from different segments of a lengthy emitter to the reference and working paths. They are also attributed to the distinction in spectral characteristics of the mirrors used for paths formation, change of a source radiation spectrum in a time interval between spectrometer scans on the reference and working paths, etc.

Let the difference of logarithms of sounding radiation spectra intensity on the reference and working paths be described by the function $\varphi(\lambda)$ :

$$
\ln I_{\lambda 0}=\ln I_{\lambda l}+\varphi_{\lambda}
$$

Then, instead of the result of measurements (4), we receive

$$
z_{\lambda}^{\prime}=z_{\lambda}+\varphi_{\lambda}
$$

Using these data to calculate $X$ and $G$ (equations (8), (9)), the following is obtained:

$$
\begin{gathered}
X^{\prime}=X+D_{\sigma \varphi} / D_{\sigma \sigma}, \\
G^{\prime}=G+\varphi_{\mathrm{av}}-\sigma_{\mathrm{av}} D_{\sigma \varphi} / D_{\sigma \sigma} .
\end{gathered}
$$

Here $X$ and $G$ are realised with a case of $\varphi(\lambda) \equiv 0$. Thus, if sounding spectra differ, the calculation leads to a constant shift of the resulting concentration and the ratio of the geometrical factors. The shift is proportional to the covariance $D_{\sigma \varphi}$ and doesn't depend on the real concentration of ozone. Obviously, that constant systematic error is subject to definition for providing the absoluteness of measurements. Note that the shift appears only if there is a distinction in relative spectra; constancy of $\varphi(\lambda)$ (proportionality of spectra) leads to zero shift because in that case $D_{\sigma \varphi} \equiv 0$.

The set of the values $\varphi_{\lambda}$ can be written as the sum of two items: 


$$
\varphi_{\lambda}=\frac{D_{\sigma \varphi}}{D_{\sigma \sigma}} \sigma_{\lambda}+q_{\lambda}, \text { where } D_{\sigma q}=0 .
$$

Such representation is a discrete analogue of the selection of contributions to $\varphi(\lambda)$ from the function $\sigma(\lambda)$ and the orthogonal to it function $q(\lambda)$. The equality $D_{\sigma q}=0$ serves here as analogue of an orthogonality condition. In statistics it implies lack of correlation of two sets of random variables. In this particular case there are no random variables, especially if random errors in $z_{\lambda}$ are not accounted. Therefore, the term 'orthogonality', despite its obvious inaccuracy, appears to be more suitable.

Let us introduce the notation

$$
\Delta z_{\lambda}=z_{\lambda}^{\prime}-G^{\prime}-X^{\prime} \sigma_{\lambda}
$$

describing a deviation of the experimentally measured values $z_{\lambda}^{\prime}$ from those calculated on the basis of determined values $X^{\prime}$ and $G^{\prime}$. In the assumption that $z_{\lambda}-G-X \sigma_{\lambda} \equiv 0$ (measurement errors are absent), we have

$$
\Delta z_{\lambda}=q_{\lambda}-q_{\mathrm{av}} .
$$

The visible difference $\Delta z_{\lambda}$ between the measured ozone absorption optical thickness and its theoretical estimation is completely determined by function $q(\lambda)$ - an orthogonal to $\sigma(\lambda)$ part of $\varphi(\lambda)$. From the expression (15) we derive quite obvious equalities $(\Delta z)_{\mathrm{av}} \equiv 0$ and $D_{\sigma \Delta z} \equiv 0$. Values $\Delta z_{\lambda}$ do not depend on the real ozone concentration. Naturally, the random errors of signals measurement will affect the values. Still, the effect of those errors can be easily minimized by averaging the results of the ozone concentration time series (for details see section 7.1). Thus, values $\Delta z_{\lambda}$ show an orthogonal to $\sigma_{\lambda}$ part of spectra difference of sounding radiation on both paths, and the dispersion $D_{\Delta z \Delta z}$ serves as a quantitative estimation of this part of the difference. The difference can be revealed when the function $\varphi(\lambda)-\varphi_{\mathrm{av}}$ is not strictly proportional to the dependence $\sigma(\lambda)-\sigma_{\mathrm{av}}$.

If only two wavelengths are used for measurements, such a proportionality is always provided, and distinction in spectra of sounding radiation cannot be revealed. Hence, systematic errors cannot be detected, while calculating ozone concentration. To somehow avoid such a situation, a number of the wavelengths should be taken. One can expect the $\varphi(\lambda)$ to include always a significant component of $q(\lambda)$, whose 'removal' by means of optical system alignment will cause a simultaneous 'removal' of a component proportional to the $\sigma(\lambda)$. Nevertheless, the method loses its absoluteness, if coincidence of sounding radiation spectra on the reference and working paths is not provided by a technique and a scheme of instrumentation alignment.

The discussed divergence in spectra of sounding radiation is expected to be a rather smooth function. That's why, the more complex trend is revealed by the ozone absorption for the set of selected wavelengths, the lesser effect will be produced by the distinction in spectra of sounding radiation.

Two simple models have been studied to assess the effect of quantity of used wavelengths 
on the uncertainty of the measured ozone concentration:

1. $\varphi_{\lambda}=\lambda-265$

2. $\varphi_{\lambda}=(\lambda-265)^{2}$, where a wavelength is set in $\mathrm{nm}$.

Various sets of working wavelengths from the list of 245, 250, 254, 258, 263, 280, 285, $295 \mathrm{~nm}$ have been used. Data on ozone absorption cross-sections for the chosen wavelengths allow us to calculate the systematic error of ozone concentration determination and a shape of a 'visible' part of spectra distinction $q_{\lambda}=\varphi_{\lambda}-\left(D_{\sigma \varphi} / D_{\sigma \sigma}\right) \sigma_{\lambda}$. The absorption cross-sections and both functions $\varphi_{\lambda}$ (scales for presentation are changed) have been given in figure 2 .

A relative change in the systematic error of the ozone concentration using various sets of wavelengths, is shown in the table 1 . The error obtained using a pair of wavelengths 295, $285 \mathrm{~nm}$ is assumed as the measurement unit. In the first case the increase in the number of working wavelengths reduces the systematic error no more than twice. In the second case the similar increase makes up almost the order in reducing the error.

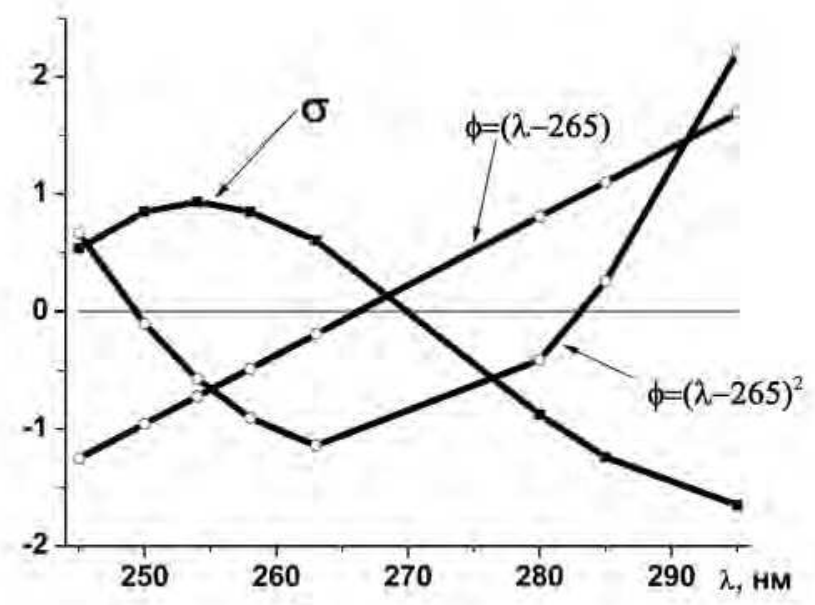

Fig. 2. Functions $\sigma_{\lambda}$ and $\varphi_{\lambda}$ for the chosen working wavelengths. The scale is changed for presentation and a shift of the ordinate axis is made.

\begin{tabular}{|c|c|l|}
\hline $\begin{array}{l}\text { Number } \\
\text { wavelengths }\end{array}$ & $\begin{array}{l}\text { The contribution to a } \\
\text { systematic error (model 1) }\end{array}$ & $\begin{array}{l}\text { The contribution to a systematic } \\
\text { error (model 2) }\end{array}$ \\
\hline 2 & 1.00 & 1.00 \\
\hline 3 & 0.79 & 0.71 \\
\hline 5 & 0.55 & 0.21 \\
\hline 8 & 0.65 & 0.14 \\
\hline
\end{tabular}

Table 1. Change of the contribution to a systematic error of ozone concentration calculation due to distinction in spectra of sounding radiation 
Graphs of the normalized (divided by $\sqrt{D_{q q}}$ ) functions $q_{\lambda}$ for sets of three $(295,285,280$ $\mathrm{nm})$, five $(295,285,280,263,258 \mathrm{~nm})$ and all eight wavelengths as well as both variants of the distinction in spectra of the sounding radiation are given in figures $3 a, 3 b$.

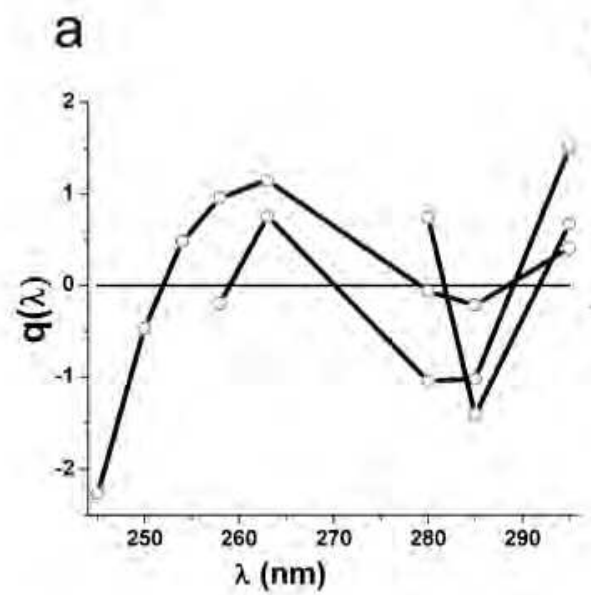

b

Fig. 3. Normalized 'visible part' in spectra distinction for cases of three, five and eight working wavelengths. $\mathrm{a}$ - distinction in spectra is described by a linear dependence, $\mathrm{b}$ - by a square-law dependence.

To assess quality and stability of the alignment, one can use the value $D_{\Delta z \Delta z}=D_{q q}$ showing an estimation of the difference of a values set $\left\{\Delta z_{\lambda}\right\}$ from zero. The condition $D_{\Delta z \Delta z}=0$ is necessary but insufficient for the coincidence of spectra of sounding radiation on both paths. It is clear that eliminating only the visible part of the distinction in spectra does not influence the measured ozone concentration. The most essential segment of the distinction remains 'invisible', and it is impossible to estimate its impact on the calculated ozone error and to introduce the corresponding correction. This correction can be only determined if the possibility of the measurement and the comparison of source spectra on the reference and working paths are provided. On the other hand, the value of $D_{\Delta z \Delta z}$ is a good criterion to assess a device alignment and can be used to maintain the quality control. If condition of spectra coincidence is realized, the system becomes an absolute measuring instrument of ozone concentration and does not require prior calibration.

\section{The OPSIS method}

There is a reason to discuss here a particular case with measurements being performed in a rather broad spectral interval, where detailed spectrum is registered, and the original results of measurements being further processed. The transformed data are used for the final calculation of concentrations of the atmosphere components absorbing radiation in a working spectral region. These data are referred to a rather narrow spectral intervals, where fine structure details of radiation absorption by atmosphere components are well pronounced. 
A method used to measure concentrations of small gas atmosphere components with an Opto-analyser AR 500 open path meter of the OPSIS firm is actually reduced to that case (Opto-analyser AR-500. User's manual, 1993). The method is based on the assumption that gases to be analyzed have narrow absorption spectral bands, and radiation source spectrum does not change in the first approximation within width of these bands. In fact, the spectral distribution of the source radiation is accounted in calculations, but its registration is carried out extremely rare. The sense of the previously mentioned preliminary data processing lies, in that case, in approximating the spectrum registered within the whole working spectral region by the $5^{\text {th }}$ order polynomial and subtracting the result from the original data. To obtain a more consistent substantiation of the method, we shall slightly extend an approach, replacing that approximation by smoothing, which will be interpreted as a convolution of original data with a nonnegative curve of a finite width. This is a version of standard signal filtration procedure (Hamming, 1989). An important requirement for the method applicability is the absence of structural details of the sounding radiation spectrum in the working spectral region which have a comparable width with the absorption bands of gases to be determined.

Elaborating the OPSIS method allows us to make smoothing of $z_{\lambda}^{\prime}$ being measured with short wavelength step (this is a mandatory requirement of the OPSIS method application) and then subtract the result from the original data. Smoothed data will be labelled with a tilde symbol. Considering equality $\widetilde{\varphi}_{\lambda}=\varphi_{\lambda}$, which is satisfied with high accuracy due to assumed by the OPSIS method smoothness of the radiation spectrum and subsequent smoothness of the function $\varphi_{\lambda}$ within the working spectral region, we derive

$$
z_{\lambda}^{\prime}-z_{\lambda}^{\prime}=z_{\lambda}-z_{\lambda}=X\left(\sigma_{\lambda}-\widetilde{\sigma}_{\lambda}\right)
$$

Thus, the spectrum of sounding radiation and the parameter connected with the g-factors are eliminated from data used to calculate gas concentration. Clearly, the method application requires two conditions be satisfied: $\widetilde{\varphi}_{\lambda}=\varphi_{\lambda}, \sigma_{\lambda} \neq \widetilde{\sigma}_{\lambda}$ in the wavelength region, employed to measure concentrations. In other words, halfwidth of the smoothing filter should be much greater than halfwidth of absorption lines, and there must be absent structural elements in the spectrum of sounding radiation with width comparable to that of absorption spectral lines of gas components to be determined. More specifically, these elements must be absent in the difference of logarithms of sounding radiation source spectrum and source spectrum registered earlier (may be under other conditions). Two variants of the method are applicable for the ozone case: a) using existing low amplitude structural features in ozone absorption spectrum near its maximum, and, b) using practically whole wavelength region captured by the Hartley band. It is evident, that in the first case the method will be less sensitive to ozone due to low values of differences $\sigma_{\lambda}-\widetilde{\sigma}_{\lambda}$, in the second case a problem arises with measuring signals in a rather broad spectral interval with a small step of a wavelength scanning. Basically, these difficulties reduce accuracy of ozone concentration measurement within the OPSIS method compared to other gases with a greater structural absorption spectrum (Opto-analyser AR-500. User's manual, 1993). 


\section{Sources of errors}

Sources of errors discussed below are inherent to any spectrometric instrument and, hence, may be viewed as of common character. It is only their numerical contribution to the uncertainty of the measurement result varies, depending on a construction of the instrument and a measurement technique.

Random errors of signals measurement arise because of imperfection of the registration system and mechanical units of the spectrometer performing wavelength setting, and also due to atmosphere transparency fluctuations generated by turbulent pulses along the path of sondage.

Each spectrometer has a systematic error of wavelength setting, following practical impossibility to define precisely the origin of the working spectral region. This kind of error may be interpreted as a systematic error in signal measurement or as a systematic error in defining ozone absorption cross-sections. Clearly, both interpretations must lead to the same numerical estimation of resulting errors for the given instrument, method of measurement and method of ozone concentration calculation.

Systematic errors of signal measurement also result from a nonlinearity of the registration system and inaccurate account of the 'electronic pedestal' being formed by dark current of a photoreceiver and by a preamplifier of signals. The construction of the TrIO- 1 device minimizes errors of such type, using neutral gauzes to attenuate radiation on the reference path, and an interference filter to align radiation source spectrum in the working spectral region. Moreover, the level of the electronic pedestal is almost two orders lower than signals being measured. Therefore, we will not consider errors of such type.

A significant role belongs to the errors generated by the instability of the radiation source and distinction of reflecting spectral coefficients of mirrors used to form the working and reference paths.

Errors in defining absorption cross-sections and cross-sections of molecular scattering for the working wavelengths as well as errors in determination of the working path length are specified within one class of errors. They are believed to have direct link with the sought ozone concentration, practically, in all existing methods for the open path meters.

Quite essential, the role of the majority of random and systematic errors may be interpreted as the distinction in sounding spectra on the working and reference paths generated by these errors. As follows, it is easy to estimate through the expression (12) contribution of each error source into the uncertainty of the calculated ozone concentration.

\section{Mathematical representation of different error sources and estimation of their influence on the error of ozone concentration determination}

Influence of the given error source on the result of ozone concentration measurement is viewed under the assumption that all other error sources are excluded. The combined effect of simultaneously acting several uncorrelated sources of errors is expressed according to well-known formula: systematic errors from different sources are summed up; dispersions of random errors from different sources are summed up. 


\subsection{Random errors of signal measurements}

Let us accept a rather natural assumption that errors $\delta S_{\lambda}$ of signal measurement at each working wavelength are of random character, and results of measurement at different wavelengths are uncorrelated with each other. This means that following equalities are realized: $\overline{\delta S_{\lambda}}=0, \quad \overline{\delta S_{\lambda} \delta S_{\lambda^{\prime}}}=0$, if $\lambda \neq \lambda^{\prime}$. Here an upper bar designates averaging over a set of repeated measurements of signals at the wavelength $\lambda$, or over a set of repeated measurements of pairs of signals at the wavelengths $\lambda$ and $\lambda^{\prime}$. Considering expression (4), it may be concluded that analogical equalities are fulfilled in relation to variables $z_{\lambda}$ : $\overline{\delta z_{\lambda}}=0, \overline{\delta z_{\lambda} \delta z_{\lambda^{\prime}}}=0$, if $\lambda \neq \lambda^{\prime}$. Let us designate the dispersion of the random variable $\delta z_{\lambda}$ as $d_{\lambda}=\overline{\delta z_{\lambda} \delta z_{\lambda}}$.

One may assume the values of $\delta z_{\lambda}$ (deviations of measured values $z_{\lambda}$ from the exact ones) as the difference of logarithms of sounding radiation spectra on the both paths appearing in the given measurement of the ozone concentration. Then, a set of $\delta z_{\lambda} \neq 0$ yields an absolute error in determination $X$ according to (12) as

$$
\delta \mathrm{X}=D_{\sigma \delta z} / D_{\sigma \sigma}
$$

and the error dispersion (while deriving the final formula, an absence of measurement errors correlation at different wavelengths and zero equality of their mean values for a set of repeated measurements are essential) as

$$
\sigma_{X}=\left[\sum_{\lambda}\left(\sigma_{\lambda}-\sigma_{\mathrm{av}}\right)^{2} d_{\lambda}\right] /\left(N^{2} D_{\sigma \sigma}^{2}\right) .
$$

If to define now the averaged over working wavelengths dispersion of $\delta z_{\lambda}$ according to

$$
d=\left[\sum_{\lambda}\left(\sigma_{\lambda}-\sigma_{\mathrm{av}}\right)^{2} d_{\lambda}\right] /\left(N D_{\sigma \sigma}\right),
$$

Then

$$
\sigma_{X}=d /\left(N D_{\sigma \sigma}\right)
$$

The same result is received if $d_{\lambda}=d$ (dispersions of measured $z_{\lambda}$ at all wavelengths are equal). Let's express now the random error in $z_{\lambda}$ through relative errors of signal measurements $\varepsilon_{\lambda 0}=\delta S_{\lambda 0} / S_{\lambda 0}$ and $\varepsilon_{\lambda l}=\delta S_{\lambda l} / S_{\lambda l}$ and link the dispersion $d_{\lambda}$ with the relative dispersion of signals. Assuming (1) and smallness of signal errors, one may see that the error in the value $z_{\lambda}$ is equal to the difference of relative errors of signals measurements on the both paths:

$$
\delta z_{\lambda}=\delta S_{\lambda 0} / S_{\lambda 0}-\delta S_{\lambda l} / S_{\lambda l}=\varepsilon_{\lambda 0}-\varepsilon_{\lambda l}
$$


Under a rather natural assumption that errors $\varepsilon_{\lambda 0}$ and $\varepsilon_{\lambda l}$ do not correlate, we obtain

$$
d_{\lambda}=s_{\lambda 0}+s_{\lambda l}
$$

where $s_{\lambda 0}=\overline{\varepsilon_{\lambda 0}^{2}}, s_{\lambda l}=\overline{\varepsilon_{\lambda l}^{2}}$ - are relative signal dispersions, easily being assessed during direct signal measurements. Thus,

$$
d=\left[\sum_{\lambda}\left(\sigma_{\lambda}-\sigma_{\mathrm{av}}\right)^{2}\left(s_{\lambda 0}+s_{\lambda l}\right)\right] /\left(N D_{\sigma \sigma}\right) .
$$

The presented expression link relative signal dispersions with the dispersion of the calculated ozone concentration. Consider an example of the currently employed method of the ozone concentration measurement for the TrIO-1 instrument. For measurement 5 wavelengths are used: 264, 268, 280, 285, $295 \mathrm{~nm}$. Relative dispersions of signals for all working wavelengths on the reference and working paths (under good weather conditions) are approximately equal and do not exceed $(0.004)^{2}$. Table values of ozone absorption crosssections give $D_{\sigma \sigma}=1.3 \cdot 10^{-35} \mathrm{~cm}^{4}$. As a consequence, the ozone concentration dispersion generated by random errors of signal measurement is about ( $3 \mathrm{ppb})^{2}$.

Let us return now to the problem of a possible stable discrepancy of sounding radiation spectra on the working and reference paths. We have noted earlier that the nonzero value $D_{\Delta z \Delta z}$ may serve as an indicator of the existence of such distinction, and, hence, be used to monitor the quality of instrument adjustment and its stability in time. Actually, the dispersion $D_{\Delta z \Delta z}$ can be never reduced to zero due to random errors of signal measurements. In particular, if a systematic distinction of spectra is absent, averaging the dispersion $D_{\Delta z \Delta z}$ over a series of ozone concentration measurements yields

$$
\overline{D_{\Delta z \Delta z}}=\left[(N-1) / N^{2} \sum_{\lambda} d_{\lambda} \geq 0 .\right.
$$

Random errors of signal measurement contribute to the value $D_{\Delta z \Delta z}$ and make it positive even when sounding spectra on the both paths coincide (in average). Therefore, even at the ideal adjustment of the instrument the dispersion $D_{\Delta z \Delta z}$ will be greater than zero.

On the other hand, values $\Delta z_{\lambda}$ are independent of the actual ozone concentration along the path. They can change only due to random errors of signal measurements. Hence, a procedure of long averaging $\Delta z_{\lambda}$ over a series of measurements is possible aiming to reduce influence of such errors. In this case, as number of measurements increases, the dispersion $D_{\overline{\Delta z} \overline{\Delta z}}$ of the averaged values $\overline{\Delta z_{\lambda}}$ tends to zero provided the systematic distinction absence of sounding radiation spectra.

\subsection{Errors of wavelength setting}

Generally, to measure signals on the working and reference paths, each wavelength is being set independently for each path. Then, $\delta \lambda_{0} \neq \delta \lambda_{l}$, i.e. an error of the wavelength setting has a 
random character and a specific random value for each path. Saving terms of the first order of smallness yields

$$
\delta z_{\lambda}=\frac{\partial \ln S_{\lambda 0}}{\partial \lambda}\left(\delta \lambda_{0}-\delta \lambda_{l}\right)+X \frac{\partial \sigma_{\lambda}}{\partial \lambda} \delta \lambda_{l}
$$

If measurements of signals on the working and reference paths at each wavelength are conducted without wavelength resetting (for example, by exchanging of paths using a moveable mirror (Bolot'ko et al., 2004, 2005), then, $\delta \lambda_{0}=\delta \lambda_{l}=\delta \lambda$ (errors of wavelength setting are equal for the working and reference paths), and

$$
\delta z_{\lambda}=X\left(\partial \sigma_{\lambda} / \partial \lambda\right) \delta \lambda
$$

In both cases deviations $\delta \lambda_{0}, \delta \lambda_{l}$ are random variables with zero mean value and they are not correlated for different wavelengths. Hence, the same is true in relation to variables $\delta z_{\lambda}$. Thus, the dispersion of the calculated ozone concentration is defined by the expression (16) and in the final form for the second case becomes

$$
\sigma_{X}=X^{2} d_{\delta \lambda}\left[\sum_{\lambda}\left(\sigma_{\lambda}-\sigma_{\mathrm{av}}\right)^{2}\left(\partial \sigma_{\lambda} / \partial \lambda\right)^{2}\right] /\left(N^{2} D_{\sigma \sigma}^{2}\right),
$$

where a natural assumption of the dispersion $d_{\delta \lambda}$ independence of the wavelength setting error from the actual value of the wavelength is employed. For the first case one can obtain a rather complicated formula, which we do not present, because the method of measurements for the TrIO-1 instrument applies, namely, to the second case. In particular, for a given set of working wavelengths the sum in the right side of (17) is approximately equal to $5.5 \cdot 10^{-72}$ $\mathrm{cm}^{8} / \mathrm{nm}^{2}$. As follows, the relative error in the ozone concentration definition caused by a random error of wavelength setting in limits $\pm 0.5 \mathrm{~nm}$ does not exceed $1.5 \%$.

Finally, if we speak about systematic error in determination of the working spectral range origin (i.e. wavelength scale shift), the error of wavelength setting is constant for all working wavelengths and does not depend on a path selection: $\delta \lambda_{0}=\delta \lambda_{l}=\delta \Lambda=$ const. In this case we have

$$
\delta z_{\lambda}=X \delta \Lambda \partial \sigma_{\lambda} / \partial \lambda
$$

and a generated systematic error in the ozone concentration is

$$
\delta X=X \delta \Lambda D_{\sigma \partial \sigma / \partial \lambda} / D_{\sigma \sigma}
$$

and has zero dispersion. For the TrIO-1 instrument $D_{\sigma \partial \sigma / \partial \lambda} \approx-1.7 \cdot 10^{-37} \mathrm{~cm}^{4} / \mathrm{nm}$, and a relative error in the ozone concentration due to wavelength scale shift of about $0.5 \mathrm{~nm}$ accounts for $0.7 \%$. Such a rather low sensitivity of the ozone error to a significant wavelength scale shift seems to be improbable. To verify that conclusion, we have made calculations with actually measured signals for the case of $0.5 \mathrm{~nm}$ wavelength shift. The resulting relative error has been found in the limits of $0.4-0.8 \%$. 


\subsection{Errors of ozone concentration definition resulted from instability of the radiation source}

Errors of such type may appear when a signal measurement at each working wavelength on the working path and reference path is separated by a considerable time interval. This may occur, if within the selected method signals on the reference path are measured rather rare, and, then, for a long time interval $\Delta t$ only signals on the working path are measured to receive a series of ozone concentrations. If one further defines difference in spectra of sounding radiation as $\varphi_{\lambda}(\Delta t)=\ln I_{\lambda 0}(t)-\ln I_{\lambda 0}(t+\Delta t)$, an originating error in the ozone concentration is derived from the expression (12). Now, expecting a linear dependence of $\varphi_{\lambda}$ on $\Delta t$, it is possible to estimate maximal time interval between signal measurements on the reference path provided forecast error does not exceed the given level. After the interval is finished, measurements have to be repeated on the reference path. Importantly enough, that changing in time of the spectral composition of the sounding radiation is much more essential than changing only its integral amplitude. Thus, in a particular case of $\varphi_{\lambda}=\operatorname{const}(\lambda)$ (a proportional variation of the source spectrum has occurred at all working wavelengths), the error in the ozone concentration generated by such instability is equal to zero.

If measurements at every wavelength on the working and reference paths follow each other, the role of errors originated by a source instability is minimized. In this case, as we have noticed earlier, an influence of random errors of wavelength setting also reduces. Thus, such variant of the method looks as more preferable.

\subsection{Uncertainties resulted from the errors in the method parameters}

Let $\delta \sigma_{\lambda}$ be a deviation of the used value of ozone absorption cross-section from the accurate one. Then, according to (8), the error of the ozone concentration calculation is

$$
X+\delta X=D_{z(\sigma+\delta \sigma)} / D_{(\sigma+\delta \sigma)(\sigma+\delta \sigma)} .
$$

From this to the first order of smallness on the value of deviation $\delta \sigma_{\lambda}$ we find

$$
\delta X \approx\left(D_{z \delta \sigma}-2 X D_{\sigma \delta \sigma}\right) / D_{\sigma \sigma} .
$$

But from relation (7) $D_{z \delta \sigma}=X D_{\sigma \delta \sigma}$. Hence,

$$
\delta \mathrm{X} / \mathrm{X} \approx-D_{\sigma \delta \sigma} / D_{\sigma \sigma}
$$

A maximal value of the covariation $D_{\sigma \delta \sigma}$ at the constant $D_{\sigma \sigma}$ is achieved when deviations are proportional to absorption cross-sections: $\delta \sigma_{\lambda}=\alpha \sigma_{\lambda}$. In this case the relative error of the ozone concentration determination equals to the relative error of absorption cross-sections definition. Influence of the error of determination of the working path length on the results of the ozone concentration calculation is evaluated on the basis of relation (6). To the first order approximation (dependence of the optical thickness of molecular scattering on the length of the working path introduces an error into calculated ozone concentration of the second order of smallness) the relative error in ozone concentration $\delta n / n=-\delta l / l$ - equals to the relative error of the path length definition. As soon as the length of the path can be measured with a high accuracy, we may ignore influence of such type errors. 
Errors in the definition of the optical thickness of molecular scattering on the working path $\tau_{\mathrm{mol} \lambda}=l \beta_{\lambda}$ (Bolot'ko et al., 2005) may appear as a result of the incorrect definition of the path length or incorrect definition of the scattering coefficient $\beta_{\lambda}$. In the latter case the error arising in the definition of variable $z_{\lambda}$ is equal to $\delta z_{\lambda}=-l \delta \beta_{\lambda}$ and, considering relation (12), we have $\delta \mathrm{X}=-l D_{\sigma \delta \beta} / D_{\sigma \sigma}$. The scattering coefficient is a smooth monotonically decreasing with wavelength function. Consequently, the most possible errors are of the type $\delta \beta_{\lambda}=\alpha \beta_{\lambda}$. For the given example $D_{\sigma \beta}=1.3 \cdot 10^{-24} \mathrm{~cm}$, and $\delta n \approx 4 \alpha$ in units of ppb. If $\alpha=0.02(2 \%$ increase of the coefficient), an originating error in ozone concentration does not exceed $0.1 \mathrm{ppb}$.

\section{Some results obtained with the open path instrument and multi-wave technique of measurement}

The need for regular measurement of surface ozone concentration has arisen with understanding of its active influence both over a climate and ecological conditions of industrial regions. In Belarus the network of stations of atmospheric air quality control has been steadily progressing to monitor such pollutants of the atmosphere as nitrogen and sulfur oxides, volatile hydrocarbons, firm particles, etc. Despite that, until 2004 there were no measurements of the surface ozone concentration regarding surface ozone as a basic participant of chemical and photochemical reactions in a boundary layer of the atmosphere as well as a greenhouse gas and the indicator of some other gases-pollutants. A significant region of Eastern Europe missed analysis of influence over an ecological condition of the atmosphere by such an active component as ozone. The impact of meteorological factors (mainly, a western air masses transfer and presence of local sources of anthropogenic photoactive atmosphere pollutants) on formation of the ozone concentration in a surface layer was not studied.

The TrIO-1 instrument designed in NOMREC has been the first instrument since 2004 to monitor surface ozone in Belarus. As was expected, five years of operation at the Minsk ozone station of NOMREC as well as reference data (Звягинцев, 2003, 2004; Звягинцев \& Кузнецова, 2002) have shown significant daily and seasonal fluctuations of the surface ozone concentration depending on meteorological and anthropogenic factors. In figure 4 day time data (ozone concentration at local noon, near 10 a.m. Greenwich Mean Time) are presented for the whole period of observations.

Clearly enough, despite some annual distinctions, seasonal changes of the surface ozone concentration have been repeated in the main features year after year. By the way, the monthly averaged values of the ozone concentration have appeared to be more informative and revealed a specific character of the seasonal course for different years of observation. In fig. 5a annual seasonal peaks (spring and summer) are visible; in autumn and winter the concentration of surface ozone is minimal. However, usually distinct spring maximum occurs not every year. In Звягинцев, 2003 one may find some valid ideas concerning a dynamic nature of the spring maximum. The point is stressed that the maximum is generated by an activation of the atmosphere vertical mixing. As a result, the air with increased ozone amount floats down from a free troposphere to a surface of the Earth. In the opposite, the summer maximum is supposed to have mainly a photochemical origin and connected with intensification of the ozone formation due to UV radiation in the polluted air. From our point of view, while considering a diurnal course of the ozone concentration in 
summertime (see figure 6), both mentioned factors contribute to a formation of the observed ozone concentration. Actually, the ozone concentration peaks in the afternoon and becomes minimal at night. Such behaviour conforms well with a daily course of activity for both basic mechanisms of formation of the surface ozone concentration: the vertical mixing in the troposphere and the photochemical ozone generation in a polluted air of the surface layer of the atmosphere. Both processes reach a maximum namely in the afternoon. There are sharp short-term fluctuations revealed in a diurnal course of ozone concentration against a background of a general smooth course. This phenomenon is typical for surface ozone and observed in all seasons and at various time of a day. The obvious reason for the registered fluctuations is a thermal and dynamic turbulence in a combination with a significant vertical gradient of the ozone concentration.

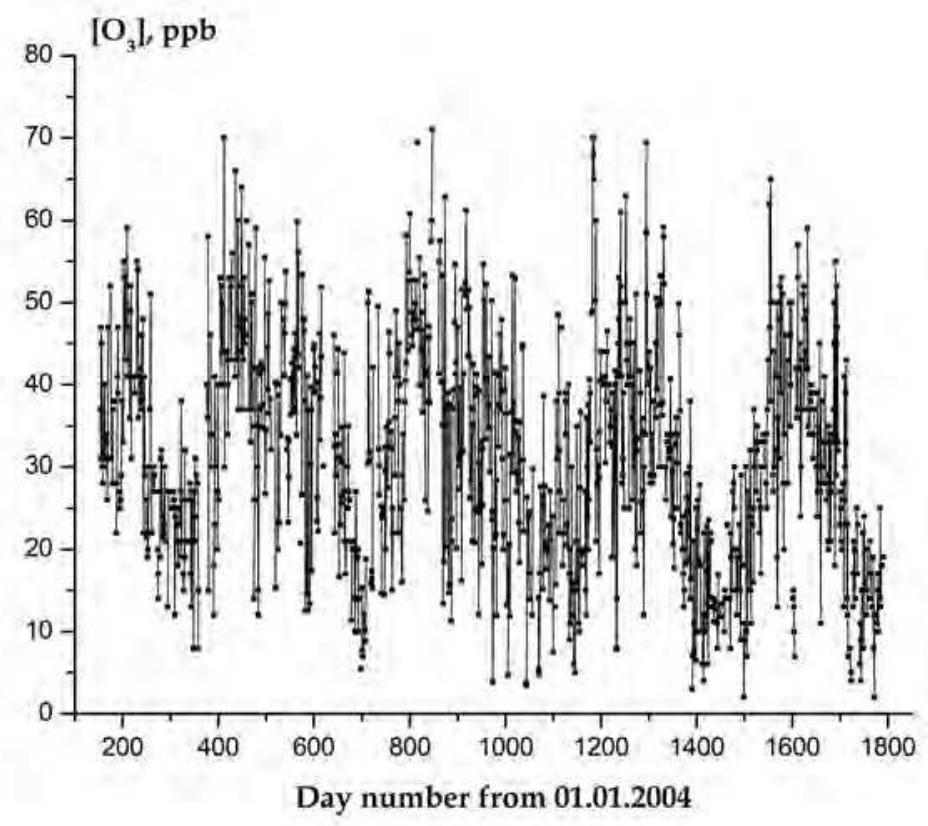

Fig. 4. Five years ozone concentration data measured at Minsk ozonometric station of NOMREC 

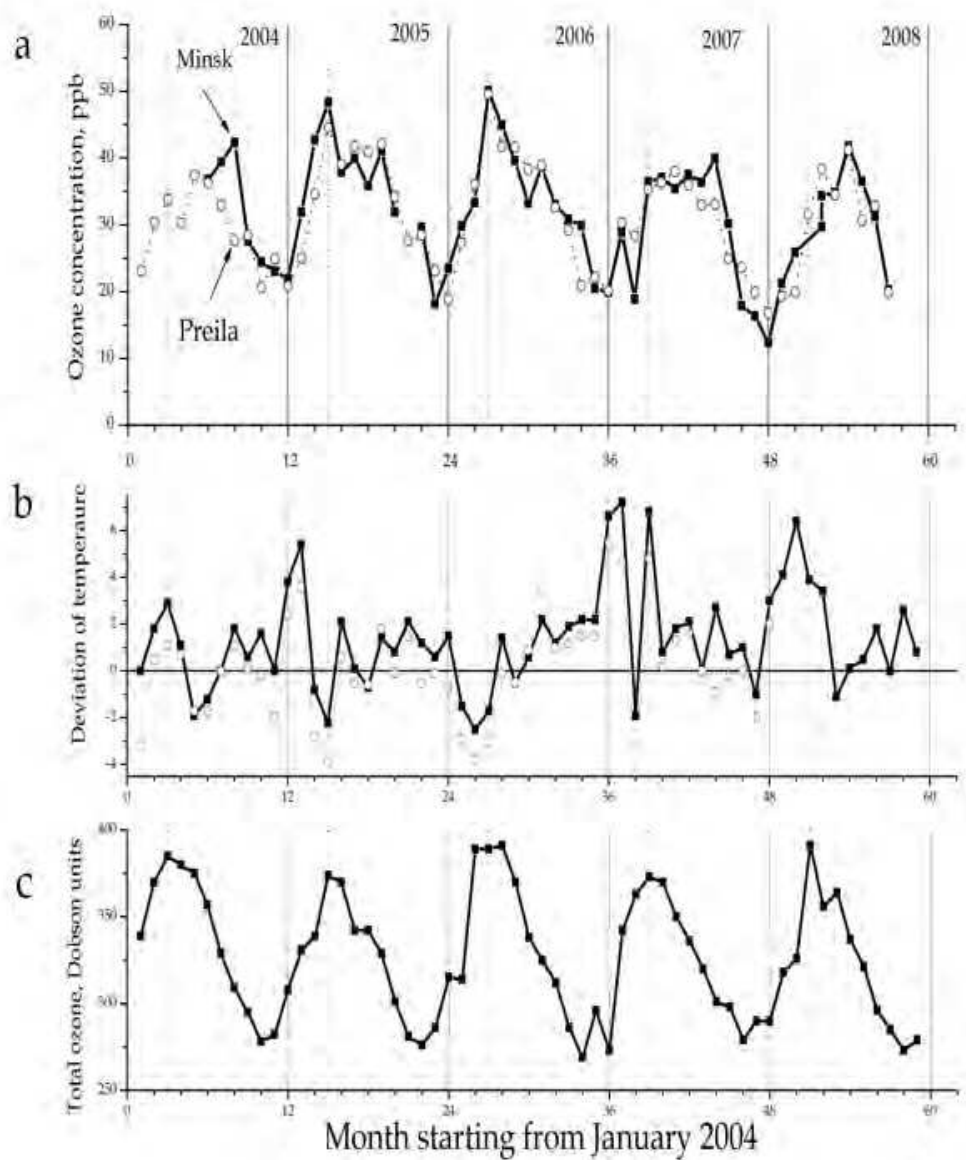

Fig. 5. Monthly averaged surface ozone concentrations in Minsk and Preila (a), deviation of monthly averaged temperature from the climatic norm in Minsk and Preila (b), monthly averaged total column ozone over Minsk (c).

One should mind, the daytime data at the NOMREC station correlate in general with data of the Preila station. As an illustration, the results of measurements for the first half of 2008 are presented in figure 7. Despite some distinctions in everyday results, there is on the whole a good correspondence in the measurements performed. The similar conclusion can be drawn, if analyzing data for different years. A quality of measurements at both stations is undoubtedly maintained at a high level, and observed discrepancies have been verified by independent measurements. In particular, very high values of the ozone concentration in the beginning of April and very low ones in May, obtained in Minsk in 2008 prove to be true as they are confirmed by parallel measurements of devices TrIO- 1 and TEI-49C. The comparative analysis of a daily course of the ozone concentration for both stations shows (figure 8) the amplitude of a daily course in Minsk rather exceeding, than that of the Preila station. This can be explained through a close location of the Preila station to the Baltic Sea 
(Звягинцев, 2004). Quite visible also, that a trend of concentration variation does not always completely correlate for both stations.

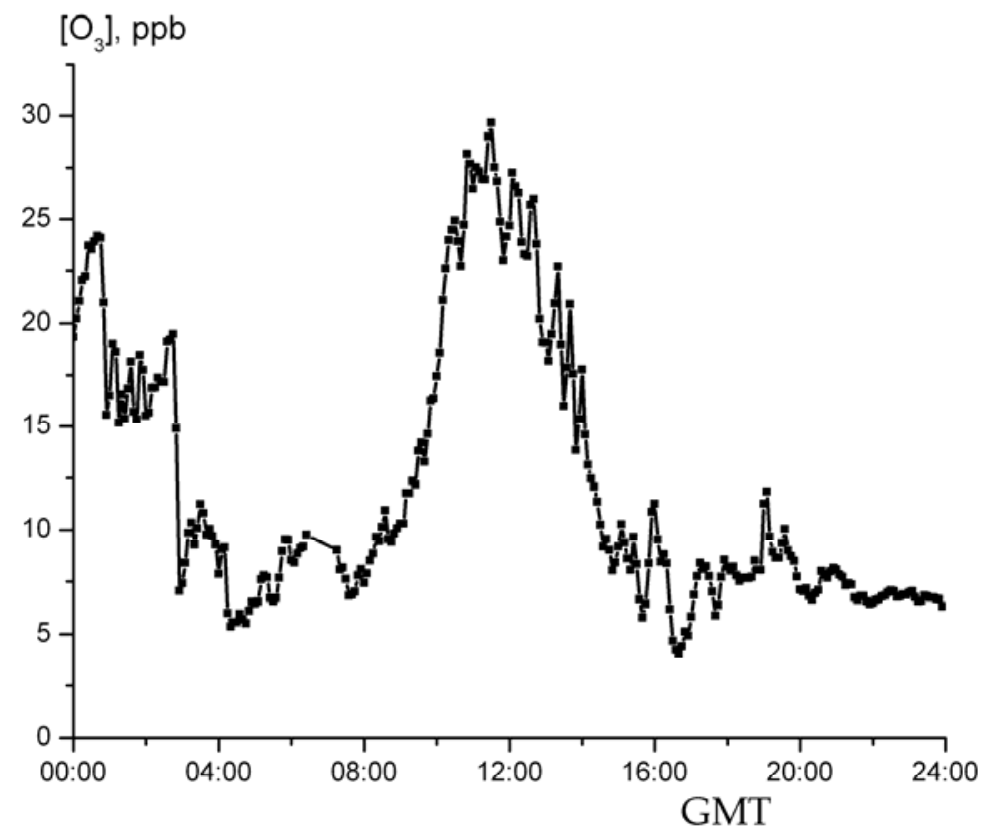

Fig. 6. A typical diurnal cause of the surface ozone concentration in Belarus. Measured on 28.08.2008. Local time is approximately 2 hours greater than Greenwich Mean Time. Short time fluctuations of the ozone concentration are clearly visible.

However, while considering monthly average values of ozone concentration, a seasonal course for both stations (figure 5a) is observed at a good match. Only for a few months for the whole period we have distinctions in figures reaching $10 \mathrm{ppb}$.

Belarus and Lithuania belong to the same climatic zone. The main differences are stipulated by the Lithuania proximity to the sea. The softer climate of Lithuania is characterized with a lower difference of climate temperature norms. The sea proximity also results in a moderate amplitude of a daily course of ozone concentration (Звягинцев, 2003).

In figure $5 b$ deviations of a monthly average temperature from a climatic norm for Minsk and similar deviations for the Preila station are presented. The interrelation between fluctuations of temperature in March and absence or presence of a spring maximum of surface ozone concentration are well exposed for both sites of the observation. For both sites of the observation amplitude of the maximum is inversely proportional to the temperature of air: the higher monthly average temperature of March, the lower amplitude of the spring maximum. In particular, in figure $5 \mathrm{~b}$ one can see the significant positive anomalies of the temperature in March to have been occurred in 2004, 2007, 2008. In these very years the spring maximum of the ozone concentration was, practically, missed (figure 5a). On the 
contrary, in 2005 and 2006 (and in 2009 too; data are not presented here) the monthly average temperature at both points was below the norm and it was accompanied with the strongly pronounced spring maximum of the surface ozone concentration.

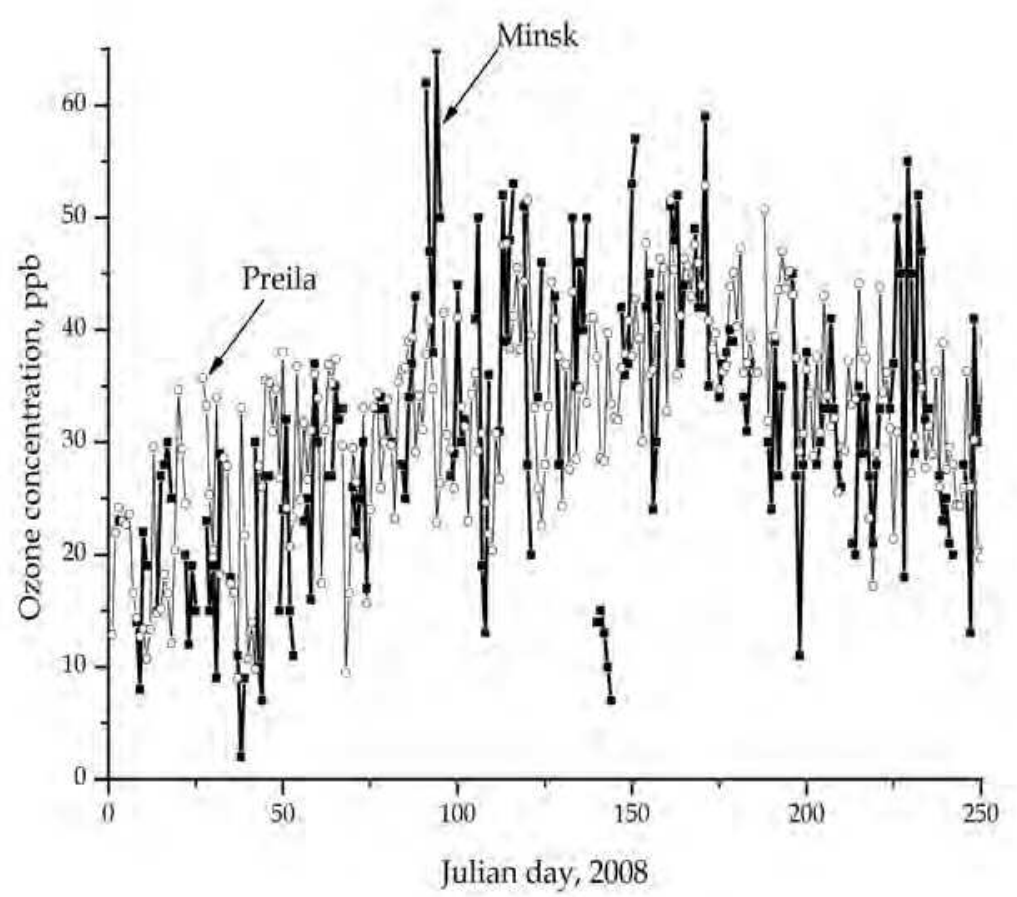

Fig. 7. Comparison of day time ozone concentrations in Minsk and Preila in 2008

Positive deviations of temperature for the Preila station are a bit lower in the most cases than on the average for Belarus, and negative deviations are a bit higher on the amplitude. However, to directly link this distinction with the difference in monthly average values of the ozone concentration does not seem to be possible. It is also difficult to analyze relation of temperature fluctuations and the surface ozone concentration in winter months, when concentration of ozone is minimal, and an influence of measurement errors can be quite essential.

An actual similarity of seasonal changes of the surface ozone concentration in Minsk and Preila, their identical dependence on the temperature (for the spring maximum) indicate that both stations most of the time are affected by the same field of the tropospheric ozone, originated from a global circulation of air masses in the Northern hemisphere. Only local factors specifically 'modulate' this field, resulting in differences of daytime results of measurements and a diurnal course. These distinctions disappear after averaging over the time interval, exceeding the period of the synoptic phenomena typical for territories of both countries (a few days and more). 


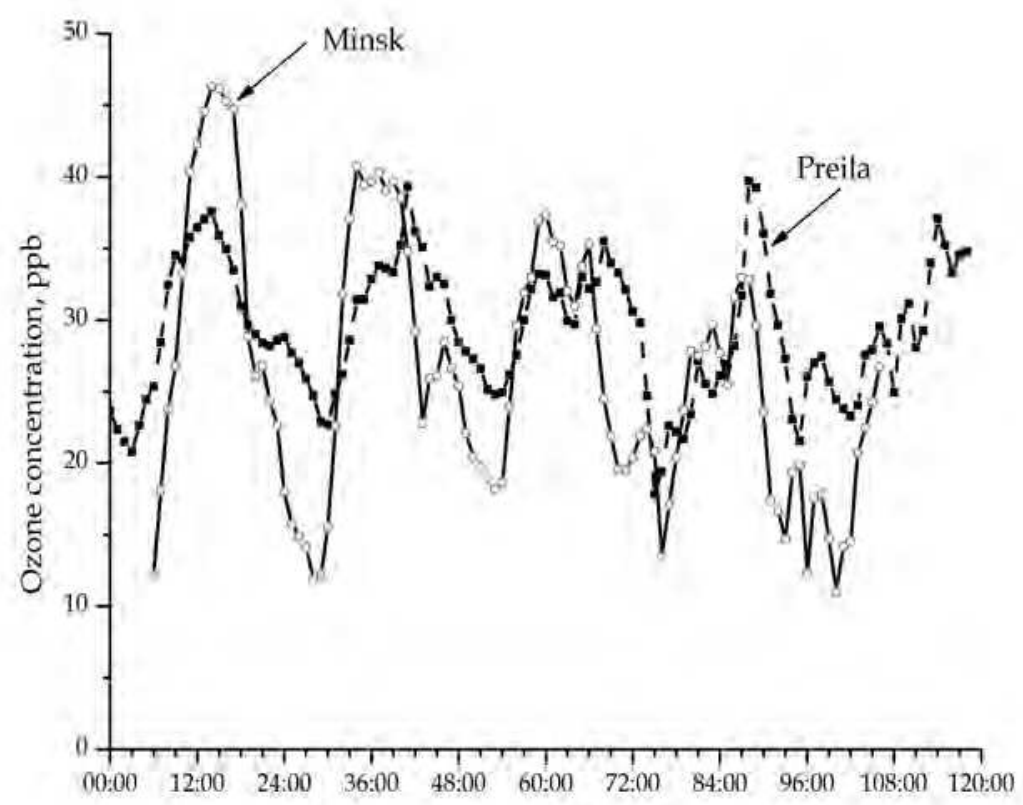

Hours starting from 00:00 24.07.2008

Fig. 8. Diurnal course of the surface ozone concentration (average hour data) in Minsk and in Preila during 24-28 July 2008.

One can view intensification of exchange with the upper troposphere under the exposition of the growing solar radiation as a main reason for the origination of the spring maximum of the surface ozone concentration. This suggestion is repeatedly expressed in Звягинцев, 2003, 2004; Звягинцев \& Кузнецова, 2002 and other papers, though, the argumentation brought herein, has an indirect character. Quite evident, that the revealed anticorrelation of surface ozone concentration with the air temperature at a time of the spring maximum is not in any agreement with the mechanism of a photochemical generation of ozone in the polluted air.

The similar situation has evolved with such a parameter of the atmosphere, as the total ozone amount (TOA). Concentration of the surface ozone is a TOA component and according to Белан et al., 2000 gain in the TOA leads to a reduction of the surface ozone concentration because of easing sun UV radiation initiating a surface photochemistry. We have compared a course of the total ozone amount over Belarus and the surface ozone concentration for the whole period of observation. As a result, any correlation appears not to be revealed (compare figures $5 \mathrm{a}, 5 \mathrm{c}$ ). 


\section{Conclusion}

The proposed multi-wave technique for determining surface ozone concentration by means of an optical open path meter is, in principle, of general type and may be modified to consider any specific realization. The given mathematical formalism allows analysing the influence of spectra discrepancy of the sounding radiation that emitted to the working and reference paths. It is shown that this discrepancy results in a constant systematic error of the ozone concentration.

The given mathematical formalism is employed to assess the role of different errors in the formation of the resulting uncertainty in the calculated ozone concentration. An idea lies in finding the link between errors in signal measurements, errors in parameters of the instrument and parameters of the calculation method and generated by those errors distinction in sounding radiation spectra on the working and reference paths. Such a distinction is simply referred to an error in a calculated ozone concentration. Analytical expressions are given to estimate role of errors of different nature. For example, for the optical open path surface ozone meter TrIO-1 it is shown that the errors in signal measurements and errors in definition of absorption cross-sections have the dominant role in the formation of the resulting error in ozone concentration measurement.

Some results received with the optical open path ozone meter TrIO- 1 within the multi-wave method are presented. A revealed link of the spring ozone maximum and average temperature is of special interest. In particular, it is obviously conflicts with the hypothesis of the photochemical origin of the spring ozone maximum.

\section{References}

Bolot'ko, L.M.; Pokatashkin, V.I.; Krasovskii, A.N. \& Tavgin, V.L. (2004). Optical trace measurer of surface ozone concentration. Journal of Optical Technology, Vol. 71, No. 1, pp. 48-50, ISSN 1070-9762

Bolot'ko, L. M.; Krasovskii, A. N.; Lyudchik, A. M. \& Pokatashkin V.I. (2005). Measurement of the terrestrial ozone concentration by absorption UV spectroscopy. Journal of Applied Spectroscopy, Vol. 72, No. 6, pp. 911-916, ISSN 0021-9037 (Print) 1573-8647 (Online)

Bolot'ko, L.M.; Krasovskii, A.N., Lyudchik, A.M. \& Pokatashkin, V.I. (2007). Optical track measurements of the near-earth ozone concentration using a multiwave technique under conditions of local thermal convection. Journal of Optical Technology, Vol. 74, No. 4, pp. 270-273, ISSN 1070-9762

Bolot'ko, L. M.; Krasovskii, A. N.; Lyudchik, A. M. \& Pokatashkin, V. I. (2008a). Ozone optical track analyzer TrIO-1 and its metrological certification features. Measurement Techniques, Vol. 51, No 10, pp. 1139-1142, ISSN 0543-1972 (Print) 15738906 (Online)

Bolot'ko, L. M.; Demin, V.S.; Krasovskii, A. N.; Lyudchik, A. M. \& Pokatashkin V.I. (2008b). Multiwavelength procedure for determining the concentration of near-ground ozone by an optical open-path measurement system. Journal of Applied Spectroscopy, Vol. 75, No 2, pp. 268-274, ISSN 0021-9037 (Print) 1573-8647 (Online)

Edner, H.; Ragnarson, P.; Spännare, St. \& Svanberg, S. (1993). Differential optical absorption spectroscopy (DOAS) system for urban atmospheric pollution monitoring. Appl.Opt., Vol. 32, No. 3, pp. 327-333, ISSN 0003-6935 (Print) 1593-4522 (Online) 
Frohlich, C. \& Shaw, G.E. (1980). New determination of Rayleigh scattering in the terrestrial atmosphere. Appl. Opt., Vol. 19, No. 11, pp. 1773-1775, ISSN 0003-6935 (Print) 15934522 (Online)

Girgzdiene, R. \& Girgzdys, A. (2003). Variations of the seasonal ozone cycles in the Preila station over the 1980-2001 period. Environmental and chemical physics, Vol. 25, No. 1, pp. 11-15, ISSN 1392-740X

Hamming, R.W. (1989). Digital filters, Prentice-Hall, ISBN 0-486-65088-X (pbk.), Englewood Cliffs, New Jersey

Jacovides, C.; Varotsos, C.; Kaltsounides, N.; Petrakis, M. and Lalas, D. (1994). Atmospheric turbidity parameters in the highly polluted site of Athens basin. Renewable Energy, Vol. 4, pp. 465-470, ISSN 0960-1481

Klausen, J.; Zellweger, Ch.; Buchmann, Br. \& Hofer, P. (2003). Uncertainty and bias of surface ozone measurements at selected Global Atmosphere Watch sites. J. Geophys. Res., Vol. 108, No. D19, pp. 4622-4632, ISSN 0148-0227

Kondratyev, K.Y. \& Varotsos, C.A. (1996). Global total ozone dynamics - Impact on surface solar ultraviolet radiation variability and ecosystems. 1. Global ozone dynamics and environmental safety. Environmental Science and Pollution Research, No. 3, pp. 153-157, ISSN 0944-1344(Print) 1614-7499 (Online)

Kondratyev, K.Y. \& Varotsos, C. (2002). Remote sensing and global tropospheric ozone observed dynamics. International Journal of Remote Sensing, Vol. 23, pp. 159-178, ISSN 0143-1161

Krasouski, A.N.; Balatsko, L.M. and Pakatashkin V.I. (2004). Surface ozone DOAS instrument with zero path, Proceedings of Quadrennial Ozone Symposium, 1-8 June 2004. Kos, Greece, Vol. 2, pp. 893-894, ISBN 960-630-103-6 960-630-105-2

Krasouski, A.; Balatsko, L.; Liudchik, A. \& Pakatashkin, V. (2006). Surface ozone DOAS measurements comparison with the instrument measuring local ozone concentrations, TECO-2006-WMO technical conference on meteorological and environmental instruments and methods of observation. Geneva, Switzerland, 4-6 December 2006. www.wmo.int/pages/prog/www/IMOP/publications/IOM-94TECO2006/P1(01)_Krasouski_Belarus.pdf

List of designated reference and equivalent methods. (2000). United States inveronmental protection agency. National exposure research laboratory. Human exposure \& atmospheric sciences division (MD-46). Research triangle park, NC 27711, 919-5412622. www.epa.gov/ttn/amtic/criteria.html

Opto-analyser AR-500. User's manual. (1993). Opsis AB - Furulund

Ozone monitoring, mapping, and public outreach. Delivering real-time ozone information to your community. (1999). United states environmental protection agency, National risk management laboratory office of research and development Cincinnati, Ohio 45268. EPA/625/R-99/007

Platt, U.; Perner, D. \& Patz, H.W. (1979). Simultaneous measurement of atmospheric $\mathrm{CH}_{2} \mathrm{O}$, $\mathrm{O}_{3}$, and $\mathrm{NO}_{2}$ by differential optical absorption. J. Geophys. Res., Vol. 84, No. C10, pp. 6329-6334, ISSN 0148-0227

Transceiver ER-130. User's manual. (1994). Opsis AB - Furulund

Varotsos, C.; Kondratyev, K.Y. and Efstathiou, M. (2001). On the seasonal variation of the surface ozone in Athense, Greece. Atmospheric Environment, Vol. 35, No. 2, pp. 315320, ISSN 1352-2310 
Varotsos, C.; Ondov, J. \& Efstathiou, M. (2005). Scaling properties of air pollution in Athens, Greece and Baltimore, Maryland. Atmospheric Environment, Vol. 39, pp. 4041-4047, ISSN 1352-2310

World Meteorological Organization (WMO). Global Atmosphere Watch measurements guide, Tech. Doc. 1073. GAW Rep. 143. (2002). Geneva, Switherland

Белан, Б.Д.; Зуев, В.В.; Скляднева, Т.К.; Смирнов, С.В. и Толмачев, Г.Н. О роли суммарного озона в фотохимическом образовании его тропосферной части. (2000). Оптика атмосферы и океана, Т. 13, № 10, с. 928-932, ISSN 0235-6880

Гиргждене, Р.; Болотько, Л.М.; Демин, В.С.; Красовский, А.Р.; Людчик, А.М. и Покаташкин, В.И. Мониторинг приземного озона в Беларуси и Литве. (2008). Природные ресурсы, No. 1, с. 60-66, ISSN 1810-9810

Звягинцев, А.М. О сходстве долговременных рядов наблюдений приземного озона на станциях Долгопрудный Московской области и Бельск, Польша. (2003). Известия РАН. Физика атмосферы и океана, Т. 39, № 4, с. 510-514, ISSN 0869-5695

Звягинцев, А. М. Основные характеристики изменчивости содержания озона в нижней тропосфере над Европой. (2004). Метеорология и гидрология, № 10, с. 46-55. ISSN 0130-2906

Звягинцев, А.М. и Кузнецова, И.Н. Изменчивость приземного озона в окрестностях Москвы: результаты десятилетних регулярных наблюдений. (2002). Известия РАН. Физика атмосферы и океана, Т. 38, № 4, с. 486-495, ISSN 0869-5695

Ультрафиолетовый трассовый газоанализатор ДОАС М1. Назначение и краткое техническое описание. (2002). ООО «Обнинская фотоника», Обнинск 


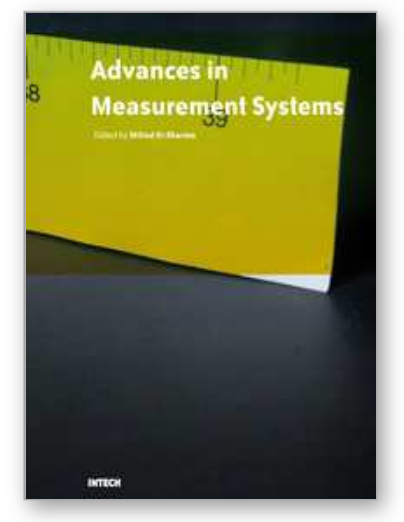

\section{Advances in Measurement Systems}

Edited by Milind Kr Sharma

ISBN 978-953-307-061-2

Hard cover, 592 pages

Publisher InTech

Published online 01, April, 2010

Published in print edition April, 2010

\section{How to reference}

In order to correctly reference this scholarly work, feel free to copy and paste the following:

Leonid Balatsko, Victar Dziomin, Aliaksandr Krasouski, Alexander Liudchik and Victar Pakatashkin (2010). Multi-Wave Differential Optical Absorption Spectroscopy Surface Ozone Measurement with Open Path Meters, Advances in Measurement Systems, Milind Kr Sharma (Ed.), ISBN: 978-953-307-061-2, InTech, Available from: http://www.intechopen.com/books/advances-in-measurement-systems/multi-wave-differential-opticalabsorption-spectroscopy-surface-ozone-measurement-with-open-path-met

\section{INTECH}

open science | open minds

\section{InTech Europe}

University Campus STeP Ri

Slavka Krautzeka 83/A

51000 Rijeka, Croatia

Phone: +385 (51) 770447

Fax: +385 (51) 686166

www.intechopen.com

\section{InTech China}

Unit 405, Office Block, Hotel Equatorial Shanghai

No.65, Yan An Road (West), Shanghai, 200040, China

中国上海市延安西路65号上海国际贵都大饭店办公楼 405 单元

Phone: +86-21-62489820

Fax: +86-21-62489821 
(C) 2010 The Author(s). Licensee IntechOpen. This chapter is distributed under the terms of the Creative Commons Attribution-NonCommercialShareAlike-3.0 License, which permits use, distribution and reproduction for non-commercial purposes, provided the original is properly cited and derivative works building on this content are distributed under the same license. 